\title{
LIVE STREAMING AND ITS RECEPTION AMONG THE RECIPIENTS
}

\section{URSZULA CHRĄCHOL-BARCZYK}

Uniersity of Szczecin, POLAND

e-mail: urszula.chrachol@wzieu.pl

\begin{abstract}
RECEIVED
4 September 2017

15 December 2017

JEL

CLASSIFICATION

M31, L82, L86

KEYWORDS

marketing, management, services, live streaming

ABSTRACT

Live streaming is becoming an increasingly popular form of transmission of information to its audience. With the help of various applications, the user can at any time record the message and put it on the network. The reach offered by live streaming is very large. The issue of publication oscillates around the problem of live streaming as an emerging form of reaching the public. The publication will analyze whether this is a positively received form of information transfer or whether it is a little developed medium, what are the opportunities in the market of live streaming and whether or not this medium can ultimately influence the building of customer relations. This issue will be presented in theoretical terms on the basis of a literature review of the area and on the secondary and own research.
\end{abstract}

\section{Introduction}

Increasing computerization, as well as the high popularity of social networks, makes it possible for modern recipients of marketing communication to have almost unlimited access to a variety of communications about the company and its services and products. Importantly, the content in question is both planned and controlled by the company as well as casual and non-formal (Rogala, 2014). 
Video content is a very important part of communication to consumers. Mark Zuckerberg, founder of Facebook, announced in early 2016 that the daily video play time on Facebook totals up to 100 million hours (How to broadcast live video on the Internet). This scale only recognizes the importance of the content being recorded and placed on the web. More and more people are using live recording and displaying it in social media or other web portals. The aim of the article is to characterize the issue of live streaming, and based on the example of actions performed by the West Pomeranian Voivodeship, showing the effectiveness of this tool.

\section{Live streaming - usage possibilities}

Live streaming is a service that transmits video content in real time. Broadcasts include sports events, concerts, interviews, conferences or presentations of new products and services ( Live streaming without secrets). Livestreaming is increasingly used by companies and individuals. With the development of technology on the market, there are more and more tools to broadcast live events.

Meerkat and Periscope were one of the first streaming dedicated applications. The first one appeared on the market in 2015, the second a month later. Meerkat has gained popularity thanks to its use by Hollywood stars, and the latter because it is a Twitter application. Table 1 provides an overview of the applications used for streaming.

Table 1. Applications used for live streaming

\begin{tabular}{|c|c|}
\hline Name of application & Description \\
\hline Periscope & $\begin{array}{l}\text { This is an application from Twitter (purchased by Twitter in March 2015), through which the users can start broadcasting their } \\
\text { event to observers - open group or specific audience, at any time. In addition, if the author makes this possible, you can return } \\
\text { to the movie with the "replay" function. The video is available } 24 \text { hours after publication. In August } 2015 \text {, it was announced } \\
\text { that it had reached a number of } 10 \text { million users worldwide. According to the website data, each day the video playback time } \\
\text { totals } 40 \text { years. } \\
\text { This application is available for Android and iOS devices. A Twitter account is required. }\end{array}$ \\
\hline Meerkat & $\begin{array}{l}\text { An application similar to Periscope, however, differs in several details. One of them is the ability to interact with recipients } \\
\text { with built-in chat and real-time commenting. In addition, the retransmission button lets you forward the video you're currently } \\
\text { viewing to your Twitter account. You need a Twitter profile to establish a Merkaat account. The application can also be linked } \\
\text { to a Facebook account. } \\
\text { After Periscope marketing, Meerkat blocked many features of the site, leading to a loss of users and a drop-in viewership. It is } \\
\text { available on Android and iOS devices. }\end{array}$ \\
\hline Facebook Live Video & $\begin{array}{l}\text { From January 2016, live streaming on Facebook was available only for verified fan pages of public persons. Since April, this } \\
\text { has been made available to all Android or iOS application users. Facebook users are alerted to the presence of their friends } \\
\text { or favorite live videos, and a special counter keeps track of the number of viewers. }\end{array}$ \\
\hline YouTube & $\begin{array}{l}\text { Also offers the possibility of live broadcast. It's enough to have your channel on YouTube to start live streaming at any time. } \\
\text { With the live chat function, you can stay in touch with your viewers, and the ability to share a link to your broadcast helps to } \\
\text { increase the reach of your stream. } \\
\text { The recording is automatically saved and after a maximum of } 12 \text { hours, appears in the Movie Manager. }\end{array}$ \\
\hline Google Hangouts & $\begin{array}{l}\text { Live broadcasts are only available to logged in users in their Google+ account. Live streaming can be broadcast as public } \\
\text { or private and can be shared on one's website. In this case, the meeting is also recorded automatically and published on the } \\
\text { YouTube channel. }\end{array}$ \\
\hline Livestream, Ustream & Allows to reach a specific audience \\
\hline
\end{tabular}

Source: ownelaboration based on: Live streaming-how to use itin marketing? Retrived from: https://poradnikprzedsiebiorcy.pl/-live-streaming-jakkorzystac-z-niego-w-marketingu; HowtobroadcastlivevideoontheInternethttp://pl.ccm.net/faq/8580-jak-nadawac-wideo-na-zywo-w-internecie.

Live streaming is increasingly being used by marketers because of the speed with which they reach their customers, their ease of communication, and the desire to watch their recordings. It is most often used for 
broadcasting events (conferences, fairs, concerts), promotional campaigns, webinars. Live broadcasting can also be a tool for building your own brand by sharing your life, showing where you are and what you do, expressing your opinions. The live broadcast service has its pros and cons. The benefits include:

- direct form of communication,

- reaching the recipient faster and easier,

- faster dissemination of information,

- reaching out to the $Z$ generation.

Moreover, they provide (Live streaming without secrets):

a) flexibility - transmission can be placed in different locations, depending on needs and requirements. Choice of place depends on having a well-developed channel on YouTube or a fan page with a large number of likes;

b) following trends - live streaming appears in many publications as one of the leading trends in 2017: "5 Social Media Trends That Will Dominate 2017", Forbes 2017, "Online Marketing Trends to Watch in 2017”, InfoGraphic Design Team 2016, "7 Online Marketing Trends That Will Dominate 2017," Forbes 2016, "Four trends that will redefine media in 2017", Marketing Week 2017;

c) unique experience for viewers - the broadcast organizer can give the viewers a unique (one-off) experience - a limited time offer - that is presenting an offer that only viewers may benefit from;

d) direct communication with customers - allows you to meet the needs of customers, answer their questions in real time;

e) interaction between customers;

f) the ability to conduct surveys;

g) access to analytical data - total number of viewers, maximum viewership, average online watch time and demographics;

h) customizable needs - color matching player, chat and logo can be adjusted.

Online transmission reaches everyone, regardless of platform - mobile, tablet and PC. This is quite significant, given that research shows that more than half of video content is currently being viewed on mobile phones. Online transmissions are not subject to physical restrictions such as the size of the room or the length of time that occurs in stationary events. Additionally, due to the fact that the broadcast is being recorded, it can be later posted anywhere in the retransmission format, accessible to people who could not watch the broadcast online.

Facebook Live streams can be broadcast publicly, people typically only come across streams broadcast by people they follow, either via notification or when a stream appears in their newsfeed. Users may also find event live streams by browsing using the Facebook Live Map. Facebook Live streams offer several types of interaction: comments, which are persistent and appear to the right of the video for viewers and below the video for broadcasters; and reactions, including Like, Love, Haha, Wow, Sad, and Angry, which, when clicked or touched by the viewer, first show a small photo of the viewer's face which turns into the reaction's emoji while floating across the video screen (Haimson, Tang, 2017).

On the other hand, there is a lack of transmission scenario, which may result in the appearance of unwanted images or content. Not everyone may accept the kind of broadcast event or the view expressed.

However, recent popular mobile video sharing platforms have been much more global in nature. Instagram, Vine and Periscope (along with other popular live-streaming apps such as Meerkat and Twitcast) are conceptualized 
as geographically agnostic in terms of content rights, with no current tools for geographical restrictions in place (Rugg, Burroughs, 2016).

\section{Onet Rano in Wesstern Pomerania}

"Onet Rano" is the first program in Poland that is broadcast live from the car - mobile studio. It takes place from Monday to Friday from 7.55 to 9.30. The program is live on the Onet Rano website and on Facebook. The program is led by Jarosław Kuźniar, until recently a TVN24 journalist leading the morning program Poranek TVN 24. Kuźniar drives his car in Warsaw every morning and talks with his guests, then he reviews the press and holds discussion in Onet studio. The host invites people from different areas and they comment on current events. "Onet Rano" features familiar faces, popular commentators from the media, politics, culture, sports, business (Onet Morning).

"Onet Rano" program has been broadcast since September 30, 2016. Kuźniar previously communicated with his viewers via the Periscope application from his private car. Premiere episode of "Onet Rano" on Friday, 30th September recorded more than 852,000 views live and more than 250 thousand views on VoD.pl. The program was also broadcast on the Facebook Live platform, where a total of over 97,000 views and post-releases were recorded (Visibility of the premiere of "Onet Morning").

From the information provided by Onet, the first 20 live episodes of the program had on average more than 800 thousand views on the portal's main site and its Facebook fan page (where they are broadcast via the Facebook Live option). The average live viewing time of each episode was 11 minutes. Then all the episodes are available at VoD.pl. On average, they recorded over 200 thousand views (Every episode of "Onet Morning" by Jaroslaw Kuźniar with a million plays, live watched for 11 minutes).

Jarosław Kuźniar says in interviews that new technologies have some advantages over television: "Today, technology and new media allow everyone to be a broadcast medium. The fact is that it gives you a lot more freedom, but (...) we are imposing on ourselves a style that enforces the highest quality. When you need to do something qualitatively good, it does not bring too much comfort. First of all, the Internet does not have a budget as big as corporate television. We realize that for the viewer it does not matter who produced it, he/she just wants it to be good. So, we do not have the comfort, but we have a lot of flexibility. Because if we talk after the program today, we draw conclusions and we know that it is necessary to improve, add here, cut off there, we change it starting from tomorrow, and we do not wait until the end of the season. We are looking at viewership results and then we decide "(Jarosław Kuźniar).

In addition, he adds that live streaming shows viewership immediately, so if something goes wrong, you can improve the next episode without waiting for the next season. The journalist also refers to an example of a wellknown American CNN station, which broadcasts the event with a 2-minute live entry, followed by a 20-minute Facebook entry.

Several programs "Onet Rano" during the year are conducted outside Warsaw, in places where Onet Rano is invited. One such place was the West Pomeranian Province, i.e. city of Szczecin. Onet Group together with the Marshal Office of the Western Pomerania Voivodeship prepared a program whose main purpose was the promotion of the Społecznik Program. This is a pioneering activity in Poland, where PLN 1.5 million will be distributed in grants to people who are active in the voivodship. 
The program is a response to the current cooperation with the NGO, which has shown that it is also necessary to support those who are not a part of an association and have fantastic ideas. Microgrants were available to everyone in Western Pomerania and could be spent for cultural activities, charity, neighborhood actions, preparation of small infrastructure (Program Społecznik start).

The day before the scheduled live broadcast, a group of Onet employees came to Szczecin. Arriving in the city, they broadcast live. The reaction of the people on Facebook was surprising. There were 260 comments in which the "Onet Rano" team was greeted, the inhabitants wrote what they could visit in Szczecin and what to do in their spare time. The recording was played 15 times in total (Figure 1) and gained 543 likes.

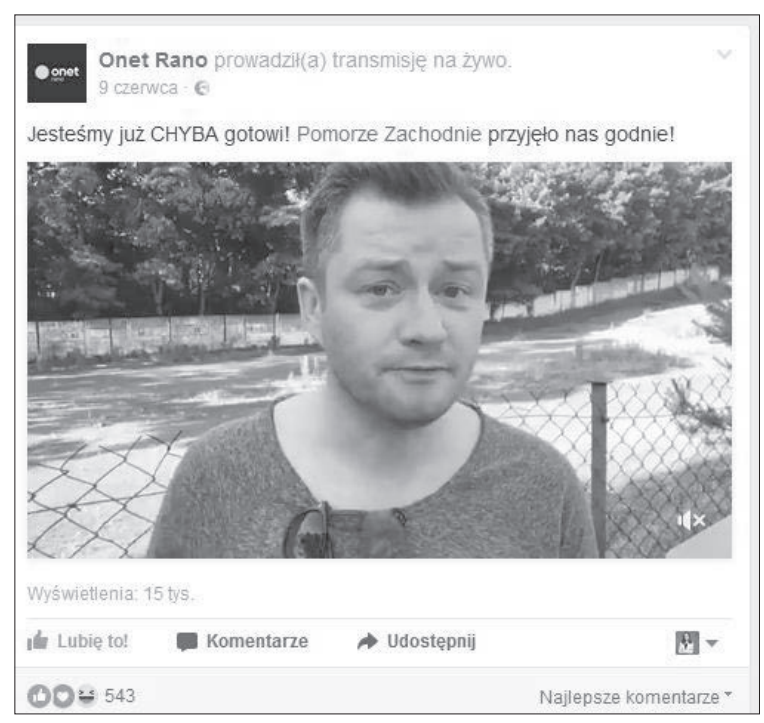

Figure 1. Facebook post recording entry to Szczecin in figures

Source: https://www.facebook.com/onetrano/?hc_ref=ART2hizlhZZ-wnu-U7b45IsGKp3fML08RNHzMUBbWPb4SW0a0h-10QdabJtLO48Yb 2Q\&fref=nf.

The next morning "Onet Rano" was held. During the 2-hour drive through Szczecin streets, Jarosław Kuźniar spoke with people who, through their involvement, made changes in the areas in which they operate. The activities presented are often consistent with the nature of the promoted Społecznik program, and are meant to motivate others. The recording (Figure 2) was displayed 91 thousand times, gained 880 likes, 622 comments were written during the program, and the recording was made available by viewers 209 times. The figures show the huge success of the promotional campaign and, secondly, the huge involvement of the live program viewers. During live streaming, the number of viewers was around 1,000 people. 


\section{onet rano.}

\section{\#WIEM jak być na bieżąco od rana}

Wyświettenia: 91 tys.
Itu Lubię to! Komentarze $\rightarrow$ Udostępnij $880 \quad$ Najlepsze komentarze
209 ponownych udostępnień

Figure 2. Facebook before recording entry to Szczecin in figures

Source: https://www.facebook.com/onetrano/?hc_ref=ART2hizlhZZ-wnu-U7b45IsGKp3fML08RNHzMUBbWPb4SW0a0h-10QdabJtLO48Yb 2Q\&fref=nf.

The example shows that live streaming has tremendous power to reach the audience. In this case, it can be said that the popularity of the program leader and the popularity of the program "Onet Rano" largely contributed to the success. The creators of the program do not limit themselves only to the live recording. Then, based on it, they make shorter recordings that are posted on different fan pages at different times. For example, the Onet 100 fan page had a presentation of a wrap-ups from a stay in Szczecin, which within 3 months of recording the program received over 960 thousand releases, 2,300 likes and 3,240 re-releases. It should be noted that Onet 100 is on Facebook one of the smaller formats of Onet and this site is liked by 110 thousand people.

\section{Conclusion}

The presented data illustrates the strength of live streaming and the number of recipients that can be reached with this tool. Numerous examples of the use of live streaming also show that it is a service involving a large number of consumers in real time. This makes it possible for the customer to be engaged in watching and commenting on the event, asking questions online, and getting answers. Therefore, live streaming is becoming increasingly popular in the organization of training. The participants can listen to it anywhere, from any mobile device and keep up with the leader's questions and discussions with other participants in the training. 
The live streaming awards as a leading trend in 2017 also confirm that this service will continue to evolve. It is up to the marketing people to use the creativity of this tool and the commitment of consumers. However, it should be kept in mind that not every live streaming shown on the net has to be a success for the company.

\section{References}

Every episode of "Onet Morning" by Jaroslaw Kuźniar with a million plays, live watched for 11 minutes. Retrieved from: http://www. wirtualnemedia.pl/artykul/kazdy-odcinek-onet-rano-jaroslawa-kuzniara-z-milionem-odtworzen-na-zywo-ogladany-przez-11minut\#.

Haimson, O.L., Tang, J.C. (2017). What Makes Live Events Engaging on Facebook Live, Periscope, and Snapchat, CHI Denver, CO, USA.

How to broadcast live video on the Internet . Retrieved from: http://pl.ccm.net/faq/8580-jak-nadawac-wideo-na-zywo-w-internecie (1.08.2017).

How to broadcast live video on the Internet. Retrieved from: http://pl.ccm.net/faq/8580-jak-nadawac-wideo-na-zywo-w-internecie.

Jarosław Kuźniar. Retrieved from: http://www.prestizszczecin.pl/magazyn/106/ludzie/niewyspany-jaroslaw-kuzniar.

Live streaming - how to use it in marketing? Retrieved from: https://poradnikprzedsiebiorcy.pl/-live-streaming-jak-korzystac-z-niegow-marketingu.

Live streaming without secrets. Retrieved from: https://filmpoint.pl/blog/live-streaming-bez-tajemnic.

Onet Morning. Retrieved from: http://wiadomosci.onet.pl/onet-rano.

Program Społecznik start. Retrieved from: http://www.wzp.pl/biuro-prasowe/biuro-prasowe/aktualnosci/rusza-program-spolecznik.

Rogala, A. (2014). The Challenges of Integrated Marketing Communications in the Era of Information Society. Marketing i Rynek, 11.

Rugg, A., Burroughs, B. (2016). Periscope, live-streaming and mobile video culture, Geoblocking and Global Video Culture. Publisher: Institute of Network Cultures.

Visibility of the premiere of "Onet Morning". Retrieved from: https://www.signs.pl/ogladalnosc-premiery-_onet-rano._,30151,artykul. html.

Cite this article aS:" Chrąchol-Barczyk, U. (2018). Live streaming and its reception among the recipients. European Journal of Service Management, 2 (26), 29-35. DOI: 10.18276/ejsm.2018.26-04. 